\title{
Aortic aneurysm presenting as conus-cauda syndrome
}

\author{
Nilesh Anil Nadkarni, Sudheer Ramattu Yousef, Kamlesh Arjundas Jagiasi, Satish V. Khadilkar \\ Department of Neurology, Grant Medical College, Sir J. J. Hospital, Mumbai, India
}

\begin{abstract}
A 65-year-old male developed retention of urine and constipation followed by subacute progressive weakness in both lower limbs. He had trauma to his back in childhood, when a wall of his house had collapsed on him without causing any deficit. On examination, he had gibbus from D11 to L2 vertebrae [Figure 1]. Sensorimotor loss affecting L1 to S1 segments on either side, but more prominent in the L4-S1 distribution, was present. A clinical diagnosis of conus-cauda syndrome was made. MRI of dorso-lumbar spine showed a saccular aneurysm arising from posterior wall of thoraco-abdominal aorta from D11-L2 level [Figure 2a and b]. There was calcification of the aneurysmal wall and its lumen contained a large eccentric lamellated thrombus. The aneurysm extended into the spinal canal by destroying D12 and L1 vertebral bodies and compressed the conus medullaris [Figure $2 \mathrm{~b}$ ]. On CT aortography, the aneurysm was $6.8 \times 6.5 \times 5.8 \mathrm{~cm}^{3}$ in dimensions [Figure 3a and $b$ ].
\end{abstract}

The patient was nonhypertensive. His serum venereal disease research laboratory (VDRL) test was negative and he had no features suggesting disorders of collagen formation. Cause of the aneurysm could not be ascertained.

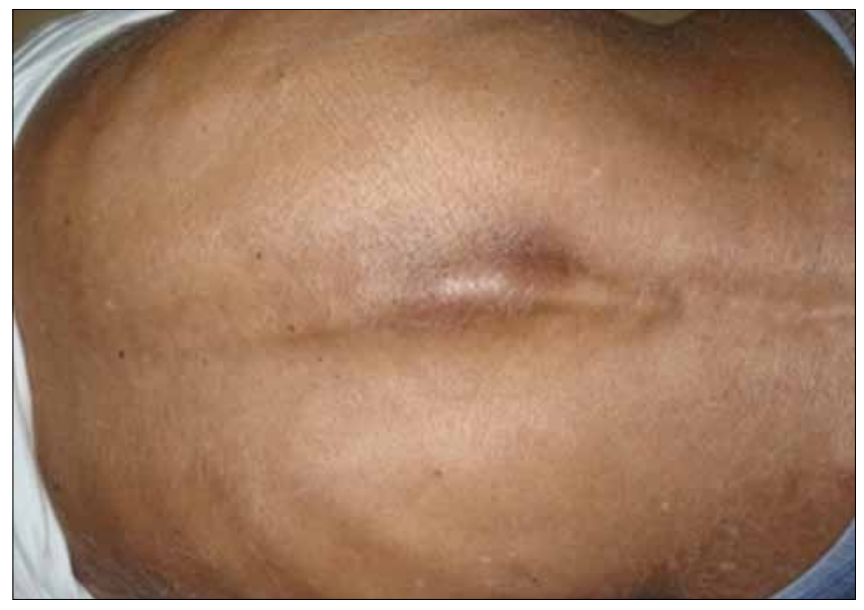

Figure 1: Gibbus of dorso-lumbar spine of the patient
Conus-cauda lesion is a rare complication of aortic aneurysm. A case of transient paraparesis as complication of an acute abdominal aortic aneurysm rupture, presumably due to occlusion of blood flow to conus medullaris, has been described. ${ }^{[1]}$ Some cases have resulted as complications of open as also endovascular aneurysmorraphy. ${ }^{[2]}$ This case highlights an unusual cause of conus cauda syndrome. Remission of paraparesis

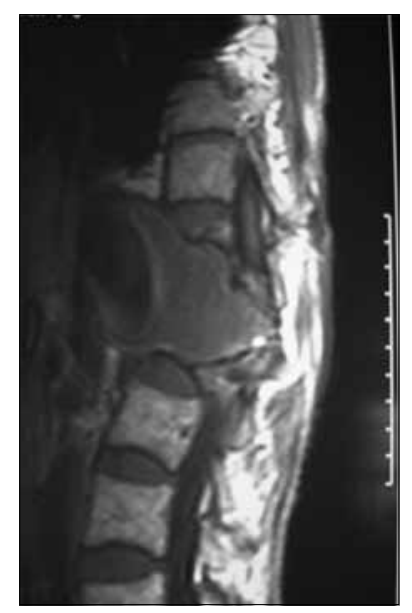

Figure 2a: Sagital T1W image of MRI dorso-lumbar spine

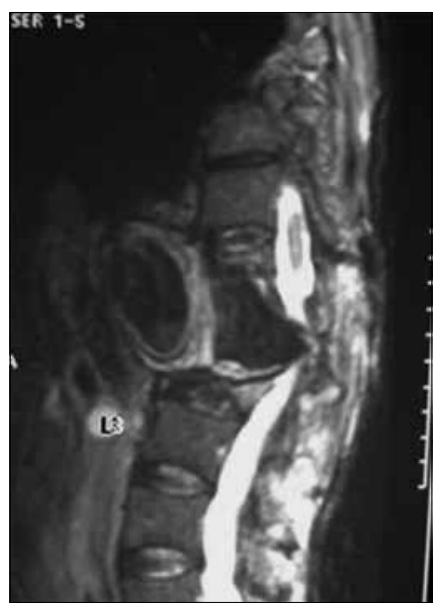

Figure 2b: Sagital T2W image of MRI dorso-lumbar spine 


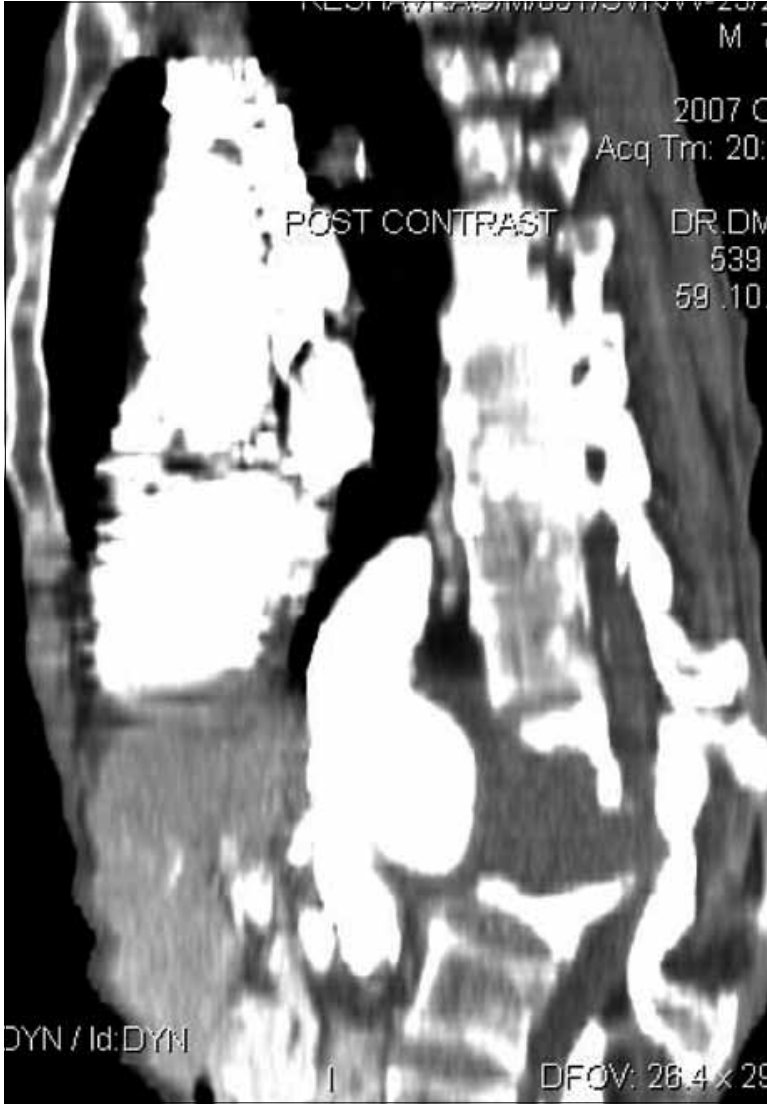

Figure 3a: Sagital view of CT aortography demonstrating the aneurysm

following aneurysmorraphy and spinal column repair can occur. ${ }^{[3]}$ However, our patient did not opt for it.

\section{Acknowledgment}

We acknowledge the contribution of Radiology Department, Sir J. J. Hospital, to this case.

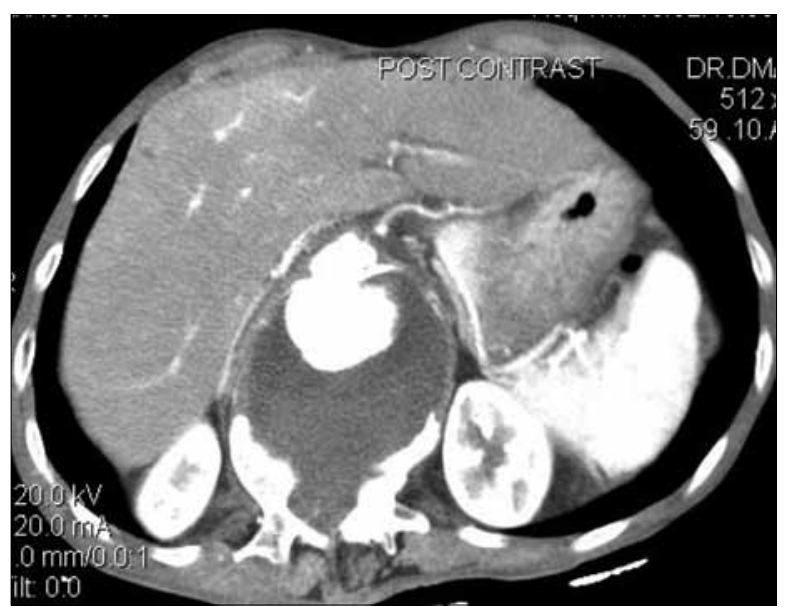

Figure 3b: Axial view of CT aortography with contrast material in the aortic lumen

Address for correspondence:

Dr. Nilesh Nadkarni,

Department of Neurology, Grant Medical College,

Sir J. J. Hospital, Mumbai, India

E-mail:drnileshnadu@gmail.com

DOI: $10.4103 / 0028-3886.55580$

\section{References}

1. Kamano S, Yonezawa I, Arai Y, Iizuka Y, Kurosawa H. Acute abdominal aortic aneurysm rupture presenting as transient paralysis of the lower leg: A case report. J Emerg Med 2005; 29:53-5.

2. Maldonado TS, Rockman CB, Riles E, Diah D, Addman MA, Jacobowitz GR, et al. Ischaemic complications after endovascular abdominal aortic aneurysm repair. J Vase Surg 2004; 40:703-10.

3. Forutan H, Herdmann J, Huber R, Saleh A, Steiger HJ, Sandmann W. Paraparesis due to pressure erosion of the thoracic spine by an aortic aneurysm: Remission of symptoms following resection of the aneurysm and vertebral reconstruction. Acta Neurochir (Wien) 2004; 146:303-8.

Accepted on 02-07-2009

Source of Support: Nil, Conflict of Interest: None declared. 